\title{
Factors Affecting Grain Quality: A Review
}

\author{
R. Yasothai* \\ Veterinary University Training and Research Centre, Tamilnadu Veterinary and Animal \\ Sciences University, Erode - 638004, Tamilnadu, India \\ *Corresponding author
}

\section{A B S T R A C T}

\begin{tabular}{l}
\hline $\begin{array}{l}\text { Ke y w o r d s } \\
\text { Grain, Quality, } \\
\text { Quantitative, } \\
\text { Quantitative }\end{array}$ \\
\hline Article Info \\
$\begin{array}{l}\text { Accepted: } \\
\text { 04 August } 2020 \\
\text { Available Online: } \\
\text { 10 September } 2020\end{array}$ \\
\hline
\end{tabular}

Cereal grains play an important role in meeting the nutrient needs of the human population. The quality of cereal products is determined by a variety of characteristics which may be assigned different significance depending on the desired end use or type of product. Grain quality is defined by several factors such as physical (moisture content, bulk density, kernel size, kernel hardness, vitreousness, kernel density and damaged kernels), sanitary (fungal infection, mycotoxins, insects and mites and their fragments, foreign material, odour and dust) and intrinsic factors (milling yield, oil content, protein content, starch content and viability). These quality characteristics of a grain are affected by its genetic traits, the growing period, timing of harvest, grain harvesting and handling equipment, drying system, storage management practices and transportation procedures. This article reviewed the various factors involved in affecting the grain quality.

\section{Introduction}

Overall quality of grain is affected by several factors includes, growing practices, time and type of harvesting, postharvest handling, storage management and transportation practices (Brooker et al., 1992). Grain quality may vary with the variety or type of grain selected by the farmer. It will be influenced by climatic and soil conditions during the growing season, cultivation practices, weather conditions at harvest, and by harvesting techniques. Producers of grain will have a number of uses for their produce; as food for the family or livestock, for seed, or for sale. The trade of grains can cover a large area entailing a variety of end usages. A number of end-users would benefit from the uniformity of supply associated with the use of grain standards, such as the commercial producers of food products e.g. beverages, baked products and animal feed, or the procurers for food security reserves. Hence grain quality is an important factor from the point of consumer. Therefore importance must be given to grain quality traits while making plant selections in segregating generations.

Milling decreases the nutrient content of the flour by the removal of nutritionally rich outer layers of the grain (Oghbaei and Prakash, 2016). Grain size and quality at harvest influence the protein content and especially the content of gluten proteins and the starch 
granule properties which determine the flour yield and quality (Angelidis et al., 2016; Baasandorj et al., 2015). Assessment of grain quality, particularly at the First point of sale, continues to be heavily reliant on manual inspection. The reason for this is largely because of the complexity of the inspection itself. Today, instrumentation exists that can accurately measures concentrations of mycotoxins and contaminants, biochemically related quality properties (protein, starch and oil), physical properties, odors, insect infestation and defects.

\section{Grain quality parameters}

Grain quality is characterized into two main factors (i) intrinsic factors, and (ii) extrinsic factors. The intrinsic factors of grain includes, color, composition, bulk density, odor, aroma, size and shape. The extrinsic factors include: age, broken grain, immature grain, foreign matter, infected grain and moisture content.

Grain quality is assessed by 2 methods

Qualitative method

Quantitative method

\section{Quantitative Method}

This method involves physical examination of all the grain ingredients. Physical evaluation is easy but qualitative in nature. It is based on analyst's skills. One must be highly trained to identify the changes in the nature of the raw material/feeds. Physical evaluation can be done immediately after receiving the grain sample before sending samples for chemical or biological evaluations.

\section{Physical evaluation}

The physical evaluation characteristics are color, texture, odor, taste, particle size (screen analysis), shape, adulteration, damage and deterioration, bulk density, storage pests (faecal material, hairs etc.,) and spot chemical tests.

\section{Quantitative method}

This method of grain evaluation involves 1 . Chemical analyses, 2. Extrinsic factors (contaminants) and 3. Intrinsic factors.

\section{Chemical analyses}

Moisture, crude protein, crude fibre, ether extract, nitrogen free extract, ash, acid insoluble ash (sand or silica), free fatty acids, biogenic amines, urea, non-protein nitrogen and amino acids.

\section{Extrinsic factors (contaminants)}

Mycotoxins, weeds, insecticide, herbicide, fungicide.

\section{Intrinsic factors}

Allergins, lectins, phytoestrogens, glucosinolates, saponins, tannins, ricin, sinapine, gossypol, lipoxygenase, urea.

\section{Techniques of measuring grain quality}

\section{Qualitative Method}

\section{Hardness}

In sorghum and maize, grain hardness is the most important parameter for assessing dry milling quality (Munck, 1995). In dry milling, a high yield of pure endosperm grits is desirable. Harder grain should give higher milling yield than softer grain (Taylor and Duodu, 2009). Several tests are used to estimate sorghum and maize grain hardness. These include bulk density tests such as test weight (AACC International, 2010), percentage of floaters and density by gas 
displacement (Paulsen et al., 2003). Maize kernels were sieved through an $8 \mathrm{~mm}$ opening round hole sieve. Maize and sorghum hardness were determined using a Tangential Abrasive Dehulling Device (TADD) (Reichert et al., 1986) by decorticating grain for $5 \mathrm{~min}$ and measure in terms of the percentage kernel removed.

\section{Test weight}

Test weight (TW) was determined by the Approved Method (AACC International, 2010) and expressed as kilograms per hectoliter. Test weight is a measure of the density of a grain and is calculated as $\mathrm{kg} / \mathrm{hL}$. Test (bushel) weight also known as volumetric weight is one of the simplest and traditional criteria used to determine quality of grain and measure of grain bulk density. It is an indicator of general grain quality and primary grain specification, normally the higher the test weight the higher the quality, and the lower the test weight the lower the quality, and grain quality decreases dramatically as grain deteriorates (Bern and Brumm, 2009). Test weight of grain is affected by many factors including moisture contents, frost damage, and maturity, growing and harvesting conditions, drying conditions, fine material, and degree of kernel damaged, and variety (Henry and Kettlewell, 1996).

Test weight is not a precise indicator of any specific grain quality attribute. Test weight remains a major pricing factor because general quality defects associated with low test weight are not reflected in any other category of the official grades. Maize with low test weight often has a lower percentage of hard endosperm and therefore produces lower yield of prime, large grits when milled (Redding et al., 1991). Both density of kernels and packing in the container influence test weight measurements. Milling companies refer to test weight as a guide to flour yield as well as the overall soundness of the grain of end use.

\section{Screening}

Screening is an important parameter in testing grain to determine the percentage of split, small, shriveled grain as well as chaff and foreign material. Screenings are determined by weighing the particles falling through a $2.0 \mathrm{~mm}$ sieve after 40 shakes. It is important for the buyer to know that the grain is full in volume and that chaff and foreign material are not excessive.

\section{Foreign Material (FM)}

Foreign material is other than grains such as sands, pieces of rocks, plastics particles, metals and pieces of glass, contaminating a particular lot of grain. In the grains trade presences of more than set percentage of FM results either low grades, price discount or lot rejection, because the higher the FM the more the cost to clean before uses.

\section{Damaged Kernel (DK)}

Damaged kernels constitute an important grading factor. It is an evident visual damaged and negatively affect their value of the grains. It is usually quantified by removing damaged kernels by hand from potions free of impurities. Main types of damaged are due to insects, heat, molds, and weathering, sprouted, frost, diseases, non-uniform maturity, shriveled (immature), broken and lack of/partial grain filling. In the grading systems or specification damaged kernels is divided into two main parts (i) heat damaged and (ii) total damaged (Freeman, 1973).

Broken grains are pieces of grains or maize which will pass through a $4.5 \mathrm{~mm}$ round hole metal sieve according to ISO 5223. 


\section{Discoloration}

Grain color is an important characteristic in grain grading. Grains discoloured by excessive heat including that caused by excessive respiration (heat damage). Grains may appear darkened, wrinkled, blistered, puffed or swollen, often with discoloured, damaged germs. The seed coat may be peeling or may have peeled off completely, giving grains a checked appearance.

\section{Size}

Size of the grain is an indicator of the energy value. The smaller the grain, the lower the metabolizable energy (ME) value, because of the increased proportion of the seed coat.

\section{Smell}

Sour odour is indicative of fermenting or mouldy grain or insect infestation. Odour similar to petroleum products is suggestive of excess of pesticides or fungicides. Heat damaged ingredients can be easily detected by their smell even when there is no visible change in color.

\section{Taste}

Each ingredient has a different taste. Bitterness in grains indicates the presence of mycotoxins. The level of salt can be detected by tasting the ingredient and feed.

\section{Touch}

Dryness and high moisture in an ingredient can be detected by feeling or touch. Clumps can be due to high moisture content or improper storage. In broken rice containing bran, if a significant amount of the bran particles adhere to the palm, it is oil containing polish and the ME value will be higher but they cannot be stored for a longer period.

\section{Sound}

The sound like spilling of coins when grains especially of maize are dropped indicates dryness. When the grain is bitten, a characteristic sound should be heard if it is dry.

\section{Quantitative Method}

\section{Moisture}

Moisture is the water content within the grain. The assessment of moisture content in seeds is an important parameter as it influences the seed quality and storage life of the seed. During the plant growth stage moisture is important for starch development as well as ensuring the filling out of the endosperm resulting in optimum milling yield. Post harvest low moisture content is expected, which is necessary for the storage life of the grain prior to being milled for its intended use. Excess moisture is detrimental as it can lead to mould growth, toxin formation, insect infestation and sprouting in storage.

Excessive rain during the final plant growth phase can result in high moisture content which will have the effect of reducing the protein content as a percentage of total weight. High moisture content above $12 \%$ may cause rejection at receivable point to prevent the risk of mould and insect growth during storage. Grain with excessively low moisture will result in a hard grain with low flour yield.

\section{Protein}

The determination of the protein content in grain is important as it is a key factor in determining grade, storage and blending during loading. The classification or grading system that exists is therefore necessary with protein content being the primary 
specification for classification. The interaction between high, intermediate and low molecular weight gluten proteins ensure strong, cohesive dough with excellent rising properties and texture.

\section{Falling Number}

Falling number is a measure of the degree of weather damage that results in sprouting. Alpha-amylase activity resulting from sprouting can reduce extensibility, strength and performance of the dough, affecting loaf volume and shelf life.

\section{Non-grain-standard properties}

Important non-grain standards includes (i) breakage susceptibility, (ii) milling quality (iii) seed viability, (iv) nutritive value, (v) mold count and carcinogen content, and (vi) insect infestation and damage (Brooker et al., 1992).

In conclusion the consumers have become accustomed over the years to demanding grain with particular qualities. Where consumers are close to the source of the grain, e.g. in local markets, their own preferences and the laws of supply and demand will control the quality of the grain. However, where grain is traded over large distances, particularly internationally, the consumer will have no direct influence over quality, and regulatory standards must be established and imposed to protect consumer rights. Therefore criteria of grain quality must be established and accepted by all parties in the grain trade. The criteria assigned to grain are the intrinsic varietal qualities and those which are environment or process induced.

\section{References}

American Association of Cereal Chemists, 2010. Cereal and Grains Association. $11^{\text {th }}$ edition.

Angelidis, G., S. Protonotariou, I. Mandala and C.M. Rosell, 2016. Jet milling effect on wheat flour characteristics and starch hydrolysis. J. Food. Sci. Technol., 53: 784-791.

Baasandorj, T., J.B. Ohm, F. Manthey and S.Simsek, 2015. Effect of Kernel Size and Mill Type on Protein, Milling Yield, and Baking Quality of Hard Red Spring Wheat. Cereal Chem., 92: 81-87.

Bern, C. and T.J. Brumm, 2009. Grain test weight deception. Iowa State University - University Extension PMR 1005, October, 2009.

Brooker, D.B., F.W.B. Arkem and C.W. Hall, 1992. Drying and storage of grain and oilseeds. New York, An AVI Book, Van Nostrand Reinhold.

Freeman, J.E., 1973. Quality factors affecting value of corn for wet milling. Trans. Am. Soc. Agric. Eng., 16: 671.

Henry, R.J. and P.S. Kettlewell, 1996. Cereal grain quality. $1^{\text {st }}$ edn., Chapman and Hall, London, UK.

Munck, L. 1995. New milling technologies and products: whole plant utilization by milling and separation of the botanical and chemical components. Pages 69-124 in: Sorghum and Millets: Chemistry and Technology. D.A.V. Dendy, ed. AACC International: St Paul, MN.

Oghbaei, M and J. Prakash, 2016. Effect of primary processing of cereals and legumes on its nutritional quality: A comprehensive review. Cogent Food \& Agriculture, 2: 1-14.

Paulsen, M. R., S.A. Watson and M. Singh, 2003. Measurement and maintenance of corn quality. Pages 159-219 in: Corn: Chemistry and Technology, 2nd edn. P. J. White and L. A. Johnson, eds. AACC International: St. Paul, MN.

Redding, E.D., C.R. Hurburgh, Jr., L.A. Johnson and S.R. Fox. Relationship among maize quality factors. Cereal 
Chem., 68: 602-605.

Reichert, R. D., R.T. Tyler, A.E. York, D.J. Schwab, J.E. Tatarynovich and M.A. Mwasaru, 1986. Description of a production model of the tangential abrasive dehulling device and its application to breeder's samples. Cereal Chem. 63:201-207.
Applications for non-wheat testing methods. Pages 197-234 in: The ICC Handbook of Cereals, Flour, Dough and Product Testing. Methods and Applications. S. P. Cauvain and L. S. Young, eds. DEStech Publications, Lancaster, PA.

Taylor, J. R. N., and K.G. Duodu, 2009.

How to cite this article:

Yasothai, R. 2020. Factors Affecting Grain Quality: A Review. Int.J.Curr.Microbiol.App.Sci. 9(09): 205-210. doi: https://doi.org/10.20546/ijcmas.2020.909.026 